Respiration 2015;90:175

DOI: $10.1159 / 000430995$

\section{Noninvasive Mechanical Ventilation in Stable Hypercapnic Chronic Obstructive Pulmonary Disease: Is Restful Sleep a Suitable Distinctive Parameter?}

\section{Antonio M. Esquinas}

Intensive Care and Non-Invasive Ventilatory Units, Hospital Morales Meseguer, Murcia, Spain

\section{Dear Editor}

Currently, there is scarce information regarding the potential impact of ventilatory modes on sleep quality over time in stable hypercapnic chronic obstructive pulmonary disease (COPD) in a home noninvasive mechanical ventilation program [1]. The factors and pathways are complex and mainly depending on complex interaction between patient requirements, lung mechanic and ventilator mode capabilities [2]. Intelligent volume-assured pressure support (iVAPS) is a hybrid mode of servoventilation providing constant automatic adjustment of pressure support to achieve the patients' target ventilatory requirements compared to high-intensity noninvasive positive pressure ventilation (HI-NPPV). However, solid data on the influence of long-term impacts of using 'target volumes' and the influence on sleep quality are required [2].

In their original study, Ekkernkamp et al. [3] described potential effects of HI-NPPV and iVAPS on sleep quality during a short period ( 6 weeks), measured by the visual analog scale, polysomnography, partial transcutaneous pressure of $\mathrm{CO}_{2}\left(\mathrm{PtcCO}_{2}\right)$ monitoring and blood gas analysis. The main result was a favorable restful sleep score during iVAPS and a greater decrease in $\mathrm{PtcCO}_{2}$ during iVAPS than HI-NPPV.

However, in this study, some other potential factors could have been taken into account to provide a proper 'global interpretation' of minor improvements reported as 'restful sleep' during iVAPS.

First, although Ekkernkamp et al. [3] enrolled stable hypercapnic COPD patients, we have to consider that there are interindividual variations in lung mechanics (compliance) and airflow obstruction (resistance) during nighttime [4]. In this line, it is important to know whether the authors performed a pulmonary function test to assess the forced expiratory volume in $1 \mathrm{~s}$ (FEV1) and the respiratory muscle strength after 6 months, as this could have influenced the results reported on alveolar ventilation as decrease in $\mathrm{PtcCO}_{2}$ and restful sleep.
Second, the authors enrolled patients who needed supplemental oxygen during NPPV in minor hypercapnic stable COPD (1.3 \pm 1.1 ). To interpret this hypoxemic condition and the ventilatory modes, it is important to know if there is overlap between obesity hypoventilation and COPD and if this condition shows variations and ventilatory mode influence after 6 weeks [5; table 1]. There is no clear explanation for this aspect and its relevance for long-term outcome.

Third, the ventilatory parameters need more evaluation as (a) the influence and level of expiratory positive airway pressure (5.8 $\pm 2.1 \mathrm{mbar}$ ) and (b) amounts of air leakage during two study ventilatory periods and how could be influenced tendency of $\mathrm{PCO}_{2}$ improvement with iVAPS period [6].

Fourth, although they mainly focused on sleep quality parameters, the authors reported that positive pressure-induced discomfort was higher during iVAPS than during HI-NPPV $(p=0.04)$, and no other significant differences were found with regard to subjective sleep quality and comfort with NPPV in the hospital. These aspects need more clarification. It would be interesting to know what environmental conditions during home mechanical ventilation were stable before and after the study [7; table 3].

Further prospective longer-term trials are necessary to consolidate this trend towards a 'restful sleep' quality and to learn more about the mechanisms of sleep improvement in stable hypercapnic COPD.

\section{References}

1 Krachman SL, Quaranta AJ, Berger TJ, Criner GJ: Effects of noninvasive positive pressure ventilation on gas exchange and sleep in COPD patients. Chest 1997;112:623-628.

2 Struik FM, Sprooten RT, Kerstjens HA, Bladder G, Zijnen M, Asin J, Cobben NA, Vonk JM, Wijkstra PJ: Nocturnal non-invasive ventilation in COPD patients with prolonged hypercapnia after ventilatory support for acute respiratory failure: a randomised, controlled, parallel-group study. Thorax 2014;69:826-834.

3 Ekkernkamp E, Storre JH, Windisch W, Dreher M: Impact of intelligent volume-assured pressure support on sleep quality in stable hypercapnic chronic obstructive pulmonary disease patients: a randomized, crossover study. Respiration 2014;88:270-276.

4 Gay PC: Chronic obstructive pulmonary disease and sleep. Respir Care 2004;49:39-51.

5 Verbraecken J, McNicholas WT: Respiratory mechanics and ventilatory control in overlap syndrome and obesity hypoventilation. Respir Res 2013; 14:132.

6 Scala R: Bi-level home ventilators for non invasive positive pressure ventilation. Monaldi Arch Chest Dis 2004;61:213-221.

7 Dybwik K, Nielsen EW, Brinchmann BS: Home mechanical ventilation and specialised health care in the community: between a rock and a hard place. BMC Health Serv Res 2011;11:115.

\section{KARGER 125}

2015 S. Karger AG, Base

$0025-7931 / 15 / 0902-0175 \$ 39.50 / 0$
Antonio M. Esquinas, MD, FCCP

Intensive Care and Non-Invasive Ventilatory Units, Hospital Morales Meseguer Avenida Marques de Los Velez s/n ES-30008 Murcia (Spain)

E-Mail antmesquinas@gmail.com 